\title{
Stability of bird repellents used to protect kea (Nestor notabilis) during aerial 1080 cereal operations
}

\author{
Michelle Crowell ${ }^{1 *}$, Lynn Booth ${ }^{2}$, Phil Cowan ${ }^{2}$, Alastair Fairweather ${ }^{1}$ and Ian Westbrooke ${ }^{1}$ \\ ${ }^{1}$ Science and Policy Group, Department of Conservation, Private Bag 4715, Christchurch 8041 \\ ${ }^{2}$ Landcare Research Ltd, PO Box 69040, Lincoln 7640 \\ *Author for correspondence: (Email: mcrowell@doc.govt.nz)
}

Published online: 9 September 2015

\begin{abstract}
Aerial poisoning with cereal bait containing 1080 toxin is known to pose a risk to the kea (Nestor notabilis), an endemic New Zealand mountain parrot. For a bird repellent to protect kea during such poisoning operations, it must be effective in bait for 4-12 weeks after the bait is manufactured, as this is when most aerial 1080 cereal operations take place. Two bird repellents have been shown to be effective with captive kea, d-pulegone and 9,10-anthraquinone. The stability of d-pulegone required further investigation because previous monitoring showed d-pulegone declined to very low levels in cereal baits 30 weeks after manufacture. Repellents were incorporated as ingredients during the normal bait manufacturing process. The estimated initial concentrations of d-pulegone in five batches of non-toxic prefeed bait and four batches of toxic bait at manufacture were only $52-88 \%$ of the nominal concentration. The superheated steam that was used to condition bait ingredients probably contributed to d-pulegone loss during manufacture. Thereafter, the estimated rate of decay of d-pulegone in storage ranged from $3.2 \%$ to $6.6 \%$ per week, so none of the batches of bait met the operational target concentration of $0.12-0.22 \% \mathrm{wt} / \mathrm{wt}$ at $4-12$ weeks after manufacture. By contrast, the concentration of anthraquinone on receipt in one batch of repellent toxic baits was very close to the nominal concentration and did not decline over a 6-month period. Future research on d-pulegone should investigate stabilisation, following which the effectiveness of d-pulegone as a bird repellent should be retested, either alone at a higher concentration or in combination with a 'secondary' repellent. Future research on anthraquinone in cereal pellets should focus on possum control, as indications are that rat kills are adversely affected by its use in cereal baits.
\end{abstract}

Keywords: anthraquinone; d-pulegone; New Zealand; non-target risk; pest control

\section{Introduction}

In New Zealand, the Department of Conservation (DOC) and others undertake control of introduced mammal pests, principally the Australian common brushtail possum (Trichosurus vulpecula), the ship rat (Rattus rattus), and the Norway rat ( $R$. norvegicus), to protect native biodiversity. A range of control methods is used, including aerial poisoning with cereal pellet baits containing 1080 (sodium fluoroacetate) (Parkes \& Murphy 2003). During such operations, risks to native non-target species are minimised by following national legal standards that, for example, limit application rates and require baits to be dyed green (Environmental Risk Management Authority 2007). DOC has strengthened these legal standards through technical assessment of non-target risks, to establish mandatory rules to be followed on land that it manages (Crowell \& Broome 2004).

In 2011, DOC carried out a risk assessment of aerially applied 1080 cereal baits, which identified an exposure risk for the kea (Nestor notabilis), an endemic New Zealand mountain parrot (M. Crowell, unpublished data). Although a lethal dose of 1080 has not been determined for kea, estimates for Australian birds suggest that parrots may be particularly susceptible (McIlroy 1984). This led DOC to make changes to operational practices, and to initiate a collaborative research project to develop, register, and implement an effective bird repellent to minimise kea deaths. In this project, criteria for an effective bird repellent were defined as:
1. Wild kea consume very little (if any) repellent-treated toxic bait

2. Possum and rat kills continue to be high when repellent is used

3. The addition of repellent does not increase the welfare impact on poisoned possums and rats

4. Repellents are effective for 4-12 weeks after bait manufacture to allow for the storage of baits prior to aerial operations

5. The additional cost of repellent is affordable

Before they can be used operationally, potential repellents need to be tested against each of these criteria. The repellents that have been investigated to date are d-pulegone and 9,10-anthraquinone ('anthraquinone'). The use of these repellents was compared with other repellents in a literature review by Spurr (2008), who recommended the combination of d-pulegone and anthraquinone as one of three possible treatments to investigate to protect kea.

\section{Review of d-pulegone and anthraquinone}

D-pulegone is extracted from plants in the genus Mentha (mint family) and has a strong minty odour, somewhere between peppermint and camphor (Baser et al. 1998; Joshi 2013). It is generally classed as a primary repellent, meaning that birds avoid it due to its unpleasant smell and/or taste, or irritancy (Mason 1990; Wager-Page \& Mason 1996). Studies have shown that birds are repelled from consuming seeds or other 
feed treated with 0.1-1\% wt/wt d-pulegone (Mason 1990; Mastrota \& Mench 1995; Avery et al. 1996; Wager-Page \& Mason 1996; Belant et al. 1997; Esther et al. 2012). Avery et al. (1996) observed post-ingestional distress in two bird species that consumed $1 \%$ and in one species that consumed $0.5 \% \mathrm{wt} / \mathrm{wt} \mathrm{d}$-pulegone, indicating that it may also act as a secondary repellent at higher concentrations - a secondary repellent differs from a primary repellent in that discomfort or illness occurs some time after consumption (Avery 2003).

Anthraquinone acts as a secondary repellent in most common applications, although it may act as a primary repellent at higher concentrations. Its consumption causes gastrointestinal irritation and vomiting if enough is consumed (Avery et al. 1997). A variety of bird species have been observed to avoid anthraquinone-treated seeds (at $0.05-0.5 \% \mathrm{wt} / \mathrm{wt}$; Avery et al. 1997, 2001; Dolbeer et al. 1998) and treated placebo or toxic pesticide baits (at 1-2.6\% wt/wt; Werner et al. 2011) after one or more initial exposures. In the USA, anthraquinone is the active ingredient in the commercial seed treatment Avipel ${ }^{\circledR}$ and in the turf or grass treatment Flight Control ${ }^{\circledR}$ PLUS.

Research on bird repellents in New Zealand has mostly trialled the use of d-pulegone and anthraquinone together, on the basis that the scent and taste of d-pulegone may act as a sensory cue to reinforce learning (Day et al. 2003, 2012; Clapperton et al. 2012, 2014). The theory is that after an initial exposure to baits treated with both repellents, birds might anticipate a repeat of gastro-intestinal discomfort (from the initial exposure to anthraquinone) when they subsequently encounter similar baits with the same strong peppermint odour and flavour (from d-pulegone).

In a study that was central to the present project, OrrWalker et al. (2012) tested whether captive kea were repelled from consuming cereal pellet baits that had been treated with d-pulegone and anthraquinone. Kea were offered a sequence of four treatments: first, untreated baits (control treatment); second, combined repellent baits with nominal concentrations of $0.17 \%$ d-pulegone and $0.1 \%$ anthraquinone (simulating repellent-treated prefeed baits); third, primary repellent baits with a nominal concentration of $0.17 \% \mathrm{~d}$-pulegone (simulating repellent-treated toxic baits); and fourth, untreated baits (control treatment). They found that mean daily consumption rates decreased significantly between untreated cereal baits and the subsequent repellent combination, and that the repellent effect was then maintained by the d-pulegone alone. Consumption then increased when kea were presented with the final treatment of untreated baits, suggesting that kea interest in untreated cereal baits was not affected.

\section{Stability of d-pulegone and anthraquinone}

Booth and Fisher (2010) analysed bait samples from the Orr-Walker et al. (2012) trial c. 30 weeks after manufacture. They found that although anthraquinone was present at the nominal concentration $(0.1 \% \mathrm{wt} / \mathrm{wt})$, the concentration of d-pulegone was much lower than the nominal concentration in both batches of repellent bait (i.e. $0.03 \%$ instead of $0.17 \%$ $\mathrm{wt} / \mathrm{wt})$. This suggested that the volatility of d-pulegone required further investigation, focusing on the period 4-12 weeks after bait manufacture, when most aerial 1080 cereal operations take place (T. Farrell, DOC, and M. Hickson, TBfree $\mathrm{NZ}$, pers. comms). The results indicated that anthraquinone did not warrant intensive monitoring, although additional measurements of anthraquinone concentration over time would be desirable.

\section{Objectives}

The main aim of this study was to estimate the initial d-pulegone concentration and the decay rate in storage for prefeed and toxic RS5 baits containing (1) a nominal concentration of $0.17 \%$ (wt/wt) d-pulegone and (2) higher nominal concentrations of d-pulegone.

Anominal concentration of $0.17 \%$ (wt/wt) d-pulegone was selected to match the nominal concentration that Orr-Walker et al. (2012) used in primary repellent and combined (with anthraquinone) repellent prefeed baits with kea. We defined the target operational concentration to be $0.17 \%$ (wt $/ w t) \pm 0.05 \%$ from 4 to 12 weeks after manufacture. We wanted to ensure that concentrations were not too high (i.e. $>0.22 \%$ ) after 4 weeks (which might repel pests, based on the literature) or too low (i.e. $<0.12 \%$ ) after 12 weeks (which might not repel kea).

Higher nominal concentrations were subsequently tested after the batches prepared with $0.17 \% \mathrm{wt} / \mathrm{wt}$ showed actual concentrations lower than the operational target.

The secondary aim of the study was to verify the Booth and Fisher (2010) observation that anthraquinone was stable in cereal baits over a 6 -month period. This timeframe coincides with the 1080 stability monitoring undertaken to support a potential registration amendment to use repellents in $0.15 \%$ 1080 cereal baits.

\section{Methods}

\section{Bait manufacture}

RS5 baits (Animal Control Products (ACP), Whanganui) were used rather than the No.7 baits used by Orr-Walker et al. (2012) because this is the type of cereal bait that is permitted by DOC for aerial 1080 cereal operations where kea may be present on land it manages. RS5 baits are the standard because they are less palatable to captive kea than No.7 baits (Blyth 2011). Orr-Walker et al. (2012) used No.7 baits in their aviary trial to provide a more conservative test of the repellents.

All non-toxic prefeed and toxic RS5 cereal baits with added repellent were manufactured by ACP. Both prefeed and toxic baits were manufactured with cinnamon lure, at nominal concentrations of $0.15 \% \mathrm{wt} / \mathrm{wt}$ and $0.3 \% \mathrm{wt} / \mathrm{wt}$ respectively, primarily to mask the presence of 1080 and act as a lure in line with industry best practice. All baits were dyed green, with the exception of one batch (LCR8PRE) manufactured solely for stability monitoring. While $0.15 \% 1080$ cereal baits are always dyed green, our development trials also used greendyed prefeed to help deter kea from sampling prefeed baits, and to reinforce the association between prefeed and toxic baits. Weser and Ross (2012) also found that green was the least preferred colour for captive kea.

D-pulegone $90 \%$ (CAS 89-82-7, 90\% active ingredient) was sourced from Penta Manufacturing Company, New Jersey, USA.Anthraquinone (Avipel Dry ${ }^{\circledR}$ CAS-84-64-1,95\% active ingredient) was sourced from Arkion Life Sciences LLC, Delaware, USA. Repellents were added to the base ingredients for RS5 baits at the mixing stage of the manufacturing process, when the cinnamon lure, green dye, and 1080 (where applicable) were added.After further mixing, the blended ingredients were treated with steam for a short period to lubricate the dye and improve pellet cohesion, and were then immediately passed through a high-pressure radial pellet press. Formed baits were then passed through a cooler and a screener to remove dust and fragments, before being dispensed into approved multiwalled paper bags that contained $25 \mathrm{~kg}$ of bait. 
Estimating initial d-pulegone concentration and decay rate in storage for baits with a nominal concentration of $0.17 \% \mathrm{wt} / \mathrm{wt}$

Booth and Fisher (2010) established, validated and explained methods for analysing d-pulegone and anthraquinone in RS5 bait matrix (Landcare Research Toxicology Laboratory Methods 090 and 078 respectively). These methods were applied in the present study, after an additional validation was performed to confirm that the analytical method for d-pulegone was unaffected by the presence of green dye and anthraquinone (L. Booth, unpublished data). The method for d-pulegone had an uncertainty of $\pm 4 \%(95 \% \mathrm{CI})$. All baits were analysed at the IANZ-accredited Landcare Research Toxicology Laboratory.

Three batches of green repellent prefeed bait (LCR2PRE, LCR4PRE, and LCR5PRE) and two batches of green repellent 1080 bait (1080 LCR Pentrial, 1080 Otira) were manufactured at a nominal concentration of $0.17 \%$ d-pulegone (i.e. the amount added during the bait manufacturing process). Prefeed batches were sampled on receipt, and at 2, 4, 8, and 16 weeks after receipt. The first batch of repellent 1080 bait (1080 LCR Pentrial) was also sampled at these times as well as 6 months after receipt. The second batch of repellent 1080 bait (1080 Otira) was sampled on receipt and three additional times up until 9 weeks after receipt. Because the time taken for baits to reach the laboratory from the factory varied from 2 to 13 days, results are reported as weeks since manufacture to standardise across batches.

Three randomly chosen 25-kg bags of bait were monitored for each batch. These were stored in conditions recommended by the manufacturer (W. Simmons, ACP, pers. comm.) - out of direct or diffused sunlight; away from fuels, solvents, and other potential contaminants; and at a stable temperature in the range of $15-25^{\circ} \mathrm{C}$. Room temperature and relative humidity were monitored and recorded at least monthly. At each sampling point, c. $100 \mathrm{~g}$ of bait was taken from each of the three bags and pooled to give a composite sample. Baits were taken from midway down the bag and the open bag was folded down to close it after sampling.

\section{Estimating initial d-pulegone concentration and decay rate in storage for baits with higher nominal concentrations}

We analysed two further pairs of batches of repellent prefeed bait and repellent 1080 bait that had been manufactured with higher nominal concentrations of d-pulegone. We were guided in our choice of nominal concentration by the monitoring results of d-pulegone in previous batches.

Small batches of undyed repellent prefeed bait $(250 \mathrm{~kg}$, LCR8PRE, nominally $0.225 \% \mathrm{wt} / \mathrm{wt} \mathrm{d}$-pulegone) and green repellent 1080 bait $(500 \mathrm{~kg}, 1080 \mathrm{LCR} 8 \mathrm{TOX}$, nominally $0.25 \%$ $\mathrm{wt} / \mathrm{wt}$ d-pulegone) were manufactured and baits were sampled and analysed on receipt and at c. 2, 4, 8, and 12 weeks later. The 1080 baits were sampled and analysed again at 4 months and 6 months after receipt, to coincide with the 1080 stability monitoring potentially needed for a registration amendment to use repellents in $0.15 \% 1080$ cereal baits.

Operational-scale batches of green repellent prefeed bait (Mataketake DPAQ, nominally $0.25 \%$ wt/wt d-pulegone) and green repellent 1080 bait (1080 Mataketake, nominally $0.29 \% \mathrm{wt} / \mathrm{wt}$ d-pulegone) were then manufactured. Monitoring followed the sampling timetable used for the LCR8PRE and LCR8TOX batches, with additional samples taken from stored prefeed and toxic baits on the days that baits were aerially applied during a pest efficacy field trial at Mataketake, West Coast.

\section{Verifying stability of anthraquinone in baits with a nominal concentration of $0.25 \% \mathrm{wt} / \mathrm{wt}$}

The first batch of repellent 1080 bait (1080 LCR Pentrial) also contained a nominal concentration of $0.25 \%(\mathrm{wt} / \mathrm{wt})$ anthraquinone, a concentration selected for a related pen trial (Cowan et al. 2014). In order to verify that anthraquinone was stable over a 6-month period (as observed by Booth \& Fisher (2010)), baits were analysed for anthraquinone upon receipt (12 days after manufacture), and 2, 4, and 6 months later following the same sampling and storage protocols described for d-pulegone. The analytical method for anthraquinone (TLM078) had an uncertainty of $\pm 3 \%(95 \% \mathrm{CI})$.

\section{Statistical analysis}

To assess the stability of d-pulegone, the concentration of d-pulegone through time was graphed in the $\mathrm{R}$ statistical computing environment and a linear regression model was fitted to the results, using a log transformation of the d-pulegone concentration (R Core Team 2013).

The model estimated the initial d-pulegone concentration at time of manufacture from the intercept at time zero. We compared the estimated concentration at manufacture to the nominal concentration of d-pulegone for each batch. The regression slope was then used to estimate the rate of decay of d-pulegone.

Based on an initial exploratory analysis, we pooled all d-pulegone results (Table 1), and fitted a regression model that treated nominal concentration $(0.17 \%$ or $>0.17 \%)$ and bait type (1080 or prefeed) as fixed effects (Fig. 1). We checked sensitivity to censoring the three samples tested after 6 months, which displayed no reduction. This had almost no effect on the model results.

We recorded the anthraquinone concentration in baits from the single batch manufactured with a nominal concentration of $0.25 \%$ (1080 LCR Pentrial) at the four sampling times to assess stability.

\section{Results}

\section{Estimated initial d-pulegone concentration and decay rate in storage}

None of the batches of bait with a nominal concentration of d-pulegone of $0.17 \% \mathrm{wt} / \mathrm{wt}$ met the target operational concentration for the period when baits are most likely to be applied aerially (i.e. $0.17 \% \pm 0.05 \%$ at $4-12$ weeks after manufacture). On average, we estimate that $79 \%$ of the nominal concentration was present at the end of the manufacture process for the 1080 batches and $75 \%$ of the nominal concentration was present in prefeed batches (Table 2). Based on the regression model (Fig. 1), the rate of decline of the current concentration was $5.3 \% \pm 0.6 \%$ per week for 1080 baits and $3.7 \% \pm 0.5 \%$ per week for prefeed baits.

None of the batches with higher nominal concentrations of d-pulegone met the target operational repellent concentration for the period when baits are most likely to be applied aerially. The initial d-pulegone concentrations for batches produced with higher nominal concentrations are shaded grey in Table 2. The proportions of nominal concentration at the end of bait manufacture were almost identical for the two batches of 
Table 1. Time since manufacture and d-pulegone concentration for five batches of prefeed RS5 bait $(0.15 \%$ $\mathrm{wt} / \mathrm{wt}$ cinnamon) and four batches of $1080 \mathrm{RS} 5$ bait $(0.3 \%$ wt/wt cinnamon). The analysis method for d-pulegone has an uncertainty of $\pm 4 \%(95 \% \mathrm{CI})$.

\begin{tabular}{|c|c|c|c|}
\hline $\mathrm{m}$ & $\begin{array}{l}\text { Weeks } \\
\text { since } \\
\text { nanufacture }\end{array}$ & $\begin{array}{c}\text { D-pulegone } \\
\text { (\% wt) }\end{array}$ & $\begin{array}{l}\text { Nominal } \\
\text { d-pulegone } \\
\text { (\% wt/wt) }\end{array}$ \\
\hline 1080 LCR Pentrial & 1 & 0.14 & 0.17 \\
\hline 1080 LCR Pentrial & 4 & 0.14 & 0.17 \\
\hline 1080 LCR Pentrial & 5 & 0.12 & 0.17 \\
\hline 1080 LCR Pentrial & 6 & 0.11 & 0.17 \\
\hline 1080 LCR Pentrial & 10 & 0.08 & 0.17 \\
\hline 1080 LCR Pentrial & 19 & 0.04 & 0.17 \\
\hline 1080 LCR Pentrial & 28 & 0.04 & 0.17 \\
\hline 1080 Otira & 2 & 0.11 & 0.17 \\
\hline 1080 Otira & 4 & 0.10 & 0.17 \\
\hline 1080 Otira & 6 & 0.10 & 0.17 \\
\hline 1080 Otira & 10 & 0.07 & 0.17 \\
\hline 1080 Otira & 11 & 0.06 & 0.17 \\
\hline Prefeed LCR2PRE & 1 & 0.10 & 0.17 \\
\hline Prefeed LCR2PRE & 4 & 0.09 & 0.17 \\
\hline Prefeed LCR2PRE & 6 & 0.09 & 0.17 \\
\hline Prefeed LCR2PRE & 10 & 0.09 & 0.17 \\
\hline Prefeed LCR2PRE & 17 & 0.06 & 0.17 \\
\hline Prefeed LCR4PRE & 1 & 0.11 & 0.17 \\
\hline Prefeed LCR4PRE & 4 & 0.09 & 0.17 \\
\hline Prefeed LCR4PRE & 6 & 0.10 & 0.17 \\
\hline Prefeed LCR4PRE & 10 & 0.10 & 0.17 \\
\hline Prefeed LCR4PRE & 17 & 0.07 & 0.17 \\
\hline Prefeed LCR5PRE & 0 & 0.15 & 0.17 \\
\hline Prefeed LCR5PRE & 2 & 0.13 & 0.17 \\
\hline Prefeed LCR5PRE & 5 & 0.14 & 0.17 \\
\hline Prefeed LCR5PRE & 8 & 0.13 & 0.17 \\
\hline Prefeed LCR5PRE & 16 & 0.08 & 0.17 \\
\hline 1080 LCR8TOX & 1 & 0.17 & 0.25 \\
\hline 1080 LCR8TOX & 3 & 0.14 & 0.25 \\
\hline 1080 LCR8TOX & 4.5 & 0.10 & 0.25 \\
\hline 1080 LCR8TOX & 9 & 0.09 & 0.25 \\
\hline 1080 LCR8TOX & 12.5 & 0.08 & 0.25 \\
\hline 1080 LCR8TOX & 18 & 0.07 & 0.25 \\
\hline 1080 LCR8TOX & 24.5 & 0.07 & 0.25 \\
\hline 1080 Mataketake & 0 & 0.21 & 0.29 \\
\hline 1080 Mataketake & 2 & 0.15 & 0.29 \\
\hline 1080 Mataketake & 4 & 0.11 & 0.29 \\
\hline 1080 Mataketake & 9 & 0.11 & 0.29 \\
\hline 1080 Mataketake & 11 & 0.11 & 0.29 \\
\hline 1080 Mataketake & 26 & 0.07 & 0.29 \\
\hline Prefeed LCR8PRE & 1 & 0.14 & 0.225 \\
\hline Prefeed LCR8PRE & 3 & 0.13 & 0.225 \\
\hline Prefeed LCR8PRE & 4.5 & 0.10 & 0.225 \\
\hline Prefeed LCR8PRE & 9 & 0.08 & 0.225 \\
\hline Prefeed LCR8PRE & 13 & 0.08 & 0.225 \\
\hline Prefeed Mataketake DPAQ & 1 & 0.14 & 0.25 \\
\hline Prefeed Mataketake DPAQ & Q 1.5 & 0.14 & 0.25 \\
\hline Prefeed Mataketake DPAQ & Q 3 & 0.09 & 0.25 \\
\hline Prefeed Mataketake DPAQ & 5 & 0.07 & 0.25 \\
\hline Prefeed Mataketake DPAQ & 9 & 0.07 & 0.25 \\
\hline Prefeed Mataketake DPAQ & Q $\quad 11$ & 0.06 & 0.25 \\
\hline
\end{tabular}

1080 bait (56\% and 55\%). For batches produced with higher nominal concentrations, we estimate that $59 \%$ of the nominal concentration of d-pulegone was present in prefeed batches at the end of bait manufacture. The rate of decline of the current concentration was $3.2 \% \pm 0.7 \%$ per week for 1080 baits and $6.6 \% \pm 1.1 \%$ per week for prefeed baits (Fig. 1).

\section{Stability of anthraquinone in baits with a nominal concentration of $\mathbf{0 . 2 5 \%}$}

The nominal concentration of anthraquinone in the toxic repellent bait batch 1080 LCR Pentrial was $0.25 \%$ (wt/wt). Sampled baits contained $0.24 \%$ anthraquinone on receipt (12 days after manufacture) and $0.22 \% 2$ months later. Baits contained $0.24 \%$ anthraquinone when sampled 4 and 6 months after receipt.
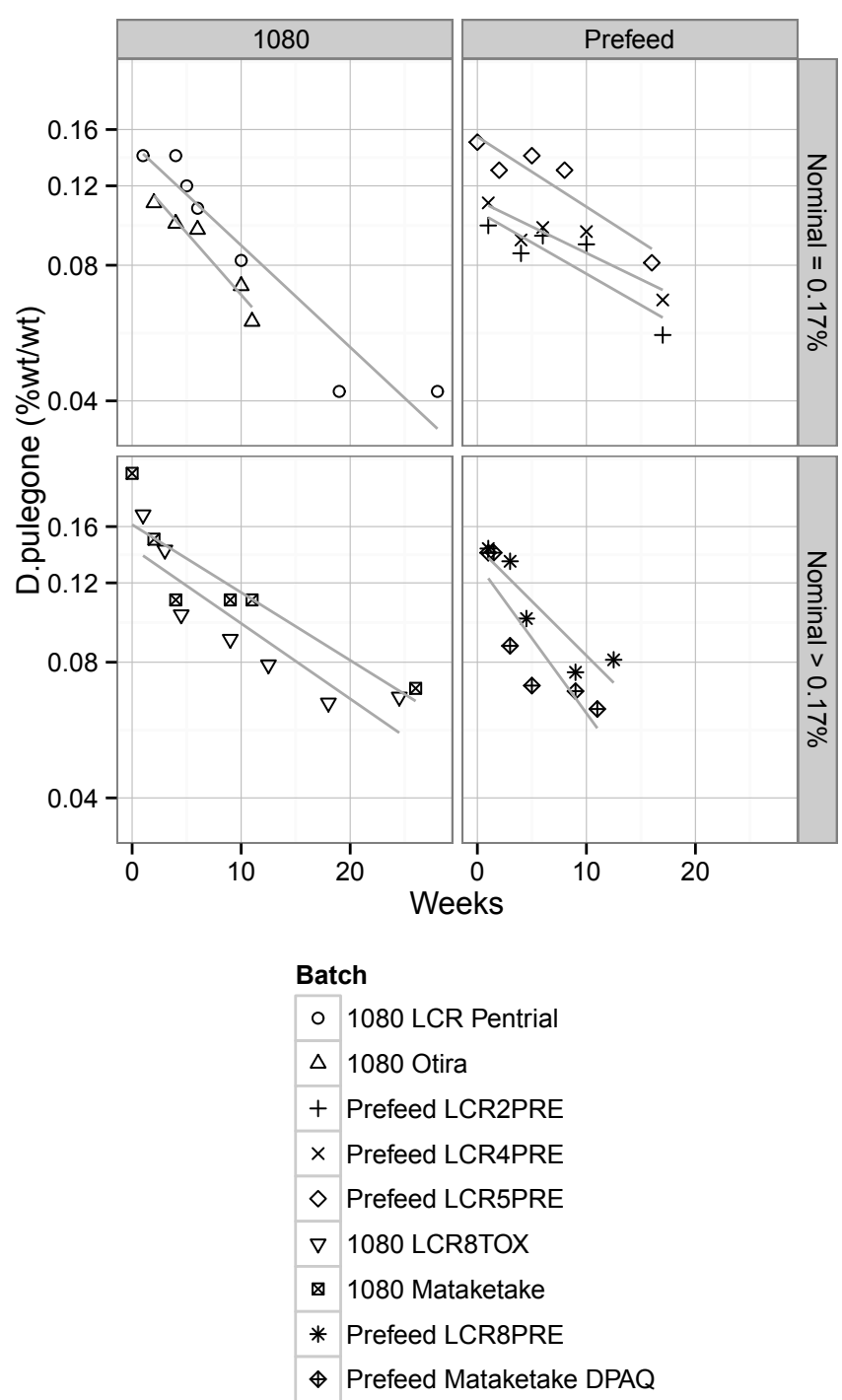

Figure 1. Linear regression model of the concentration of d-pulegone in five batches of prefeed RS5 bait and four batches of 1080 RS5 bait manufactured with d-pulegone. Batch details and the actual concentrations associated with each data points are provided in Table 1 . The analysis method for d-pulegone has an uncertainty of $\pm 4 \%(95 \% \mathrm{CI})$. Note the log scale on the vertical (y) axis. 
Table 2. Estimated initial d-pulegone concentration, nominal d-pulegone concentration and estimated proportion of nominal d-pulegone concentration in five batches of prefeed RS5 bait ( $0.15 \% \mathrm{wt} / \mathrm{wt}$ cinnamon) and four batches of $1080 \mathrm{RS} 5 \mathrm{bait}$ $(0.3 \% \mathrm{wt} / \mathrm{wt}$ cinnamon). Initial d-pulegone concentration is estimated for the end of the manufacturing process, using a linear regression model. Estimated proportion of nominal concentration is calculated as the estimated initial d-pulegone concentration divided by the nominal d-pulegone concentration.

\begin{tabular}{llcccc}
\hline Batch, date of manufacture & Bait type & $\begin{array}{l}\text { Estimated initial } \\
\text { d-pulegone } \\
\% \text { wt/wt }\end{array}$ & $\begin{array}{l}\text { 95\% confidence } \\
\text { interval }\end{array}$ & $\begin{array}{l}\text { Nominal } \\
\text { d-pulegone } \\
\% \text { wt/wt }\end{array}$ & $\begin{array}{l}\text { Estimated } \\
\text { proportion of } \\
\text { nominal } \\
\text { concentration }\end{array}$ \\
\hline 1080 LCR Pentrial, 21/2/13 & 1080 & 0.15 & $0.13-0.18$ & 0.17 & $88 \%$ \\
1080 Otira, 31/5/13 & 1080 & 0.12 & $0.10-0.14$ & 0.17 & $71 \%$ \\
LCR2PRE, 21/2/13 & Prefeed & 0.11 & $0.09-0.12$ & 0.17 & $65 \%$ \\
LCR4PRE, 21/2/13 & Prefeed & 0.12 & $0.10-0.14$ & 0.17 & $71 \%$ \\
LCR5PRE, 12/3/13 & Prefeed & 0.15 & $0.13-0.18$ & 0.17 & $88 \%$ \\
1080 LCR8TOX, 16/9/13 & 1080 & 0.14 & $0.12-0.16$ & 0.25 & $56 \%$ \\
1080 Mataketake, 5/11/13 & 1080 & 0.16 & $0.14-0.19$ & 0.29 & $55 \%$ \\
LCR8PRE, 16/9/13 & Prefeed & 0.15 & $0.13-0.18$ & 0.225 & $67 \%$ \\
Mataketake DPAQ, 1/11/13 & Prefeed & 0.13 & $0.11-0.15$ & 0.25 & $52 \%$ \\
\hline
\end{tabular}

\section{Discussion}

\section{Loss of d-pulegone during manufacture}

Our results suggest that there was a high loss of d-pulegone during the manufacturing process. The magnitude of loss was greater for the batches with higher nominal concentrations, with an estimated $65-88 \%$ of nominal d-pulegone concentration when baits were manufactured at $0.17 \%$ nominal concentration, but only $52-67 \%$ of nominal concentration for batches produced with higher nominal concentrations. It seems that as we increased the nominal d-pulegone concentration, either less d-pulegone was incorporated into baits or d-pulegone dissipated more quickly during manufacture.

The odour of d-pulegone was very strong in the factory, suggesting that it vaporises during manufacture (W. Simmons, pers. comm.). Some of the loss of d-pulegone could have resulted from adhesion of the liquid to the machinery during the mixing process, and/or an interaction between d-pulegone and the cinnamon lure, as the lure contains solvents and volatile carriers. However, we do not think that the latter suggestion is likely, as there was no consistent difference in the proportion of nominal d-pulegone present in prefeed baits (lured with $0.15 \%$ cinnamon) and toxic baits (lured with $0.3 \%$ cinnamon). Rather, it is most likely that this loss was caused by the d-pulegone being volatised by the superheated steam that was used to condition the pellet ingredients immediately prior to pelletising (W. Simmons, pers. comm.). Therefore, omission of the steam treatment might reduce d-pulegone loss, although this would then affect bait quality and robustness. Surface treatment of baits was considered as an alternative; however, a small pilot trial of RS5 baits surface treated with a d-pulegone solution recorded similar or higher rates of manufacturing loss (unpublished data; K. Stafford, EPRO, pers. comm.).

This is the first time that the concentration of d-pulegone in repellent baits has been analysed and compared with the nominal level. None of the previous New Zealand studies that have applied d-pulegone to the surface of cereal baits (Day et al. 2000), carrot baits (Day et al. 2000), dough baits (Day et al. 2003; Clapperton et al. 2014), or wheat (Clapperton et al. 2012; Day et al. 2012) have included an analysis of the concentration of d-pulegone in the baits or wheat - although baits were used within 1-3 days of being manufactured. Likewise, the concentration of d-pulegone was not measured when it was assessed as a surface repellent for rice (Avery et al. 1996), millet (Belant et al. 1997), apple (Wager-Page \& Mason 1996), bird conditioning feed (Mason 1990; Mastrota \& Mench 1995), clay granules (Mastrota \& Mench 1995), and maize seeds (Esther et al. 2012). Given the low retention of d-pulegone observed in our baits, we recommend that the actual concentration of d-pulegone in or on baits is analysed in any future repellent research, even where the repellent-treated baits will be used immediately.

\section{Dissipation of d-pulegone in storage}

The dissipation of d-pulegone has not been monitored in other studies because the repellent-treated baits or seeds have been used within a few days of preparation, whereas stability in storage is essential for its use in aerial 1080 cereal operations.

Our estimates of the decay rate for d-pulegone ranged from $3.2 \%$ to $6.6 \%$ per week, with no obvious explanation for the variation in observed rates. Of the batches manufactured with a nominal concentration of $0.17 \%$ d-pulegone, three batches contained less than the operational target on receipt (8-12 days after manufacture), one batch met the target for 5 weeks, and one batch met the target for 8 weeks. In the batches manufactured with higher nominal concentrations of d-pulegone, two batches met the operational target for 1.5-2 weeks and two batches met the target for 3 weeks. Therefore, increasing the nominal concentration of d-pulegone did not help to achieve our operational target.

Since d-pulegone is used as a flavouring agent, food technology may provide options for reducing the loss of d-pulegone, both during manufacture and in storage. Retention of flavour and aroma is a requirement for many processed foods, and a range of encapsulation processes have been developed to extend their shelf life (Madene et al. 2005). It is possible that such technology could help to control the release of d-pulegone over a longer timeframe. 


\section{Operational target concentration of d-pulegone}

It is important to consider whether the operational target concentration of d-pulegone could be lowered, as this could help to address the losses during the manufacturing process and in storage. We applied our bait stability monitoring results to the Orr-Walker et al. (2012) aviary trials, to estimate the likely d-pulegone concentration that was offered to captive kea in the repellent prefeed baits over the trial period of $\mathrm{c}$. 12 weeks. Their No.7 prefeed baits were manufactured with a nominal concentration of $0.17 \%$ d-pulegone and contained $0.03 \%$ d-pulegone 30 weeks after manufacture (Booth \& Fisher 2010), which is consistent with the decay rates generated by our regression model. Our trial included three batches of prefeed bait manufactured with the same nominal concentration; these batches contained $0.10-0.15 \%$ d-pulegone on receipt and $0.09 \%$ d-pulegone 10 weeks after manufacture. Based on these samples, the aviary trial baits are estimated to have contained c. 0.09-0.15\% d-pulegone during the trial.

Based on this estimation, the operational target concentration for d-pulegone could be reduced from the current range $(0.12-0.22 \%)$ to the lower range of $0.09-0.15 \%$ d-pulegone. However, we believe that this would be risky for two reasons. First, the Orr-Walker et al. (2012) observations were with captive kea and may not reflect consumption in the wild. Second, the lower end of the likely concentration range is only slightly higher than the estimated d-pulegone concentration for 1080 baits used at the Otira operation $(0.07 \%$ $\mathrm{wt} / \mathrm{wt}$ ), where $15 \%$ of monitored wild kea died from consuming 1080 baits (van Klink \& Crowell 2015).

Therefore, we recommend that the current target operational concentration of $0.17 \pm 0.5 \% \mathrm{wt} / \mathrm{wt}$ d-pulegone from 4 to 12 weeks after manufacture be maintained.

\section{Stability of anthraquinone}

The concentration of anthraquinone on receipt (12 days after manufacture, $0.24 \%$ ) was very close to the nominal concentration $(0.25 \%)$ and did not decline over a 6 month period, consistent with the results of Booth and Fisher (2010). Anthraquinone meets the stability criterion set for the development of an effective bird repellent for use in aerial 1080 cereal operations.

\section{Conclusions}

The target operational concentration of $0.17 \% \mathrm{wt} / \mathrm{wt} \pm 0.5 \%$ d-pulegone was not maintained for 4-12 weeks in any batch of repellent cereal bait in this study, using current manufacturing methods. If means can be found to stabilise d-pulegone in baits, we see two possibilities for developing an effective strategy involving this repellent: it could be used either as a primary repellent at a higher concentration or as a sensory cue for a secondary repellent. To investigate its potential as a primary repellent, behavioural trials would be required to see whether (ideally wild) kea avoid consuming cereal baits containing at least $0.12 \% \mathrm{wt} / \mathrm{wt} \mathrm{d}$-pulegone.

With regard to the second strategy, it has already been demonstrated that captive kea consume fewer baits when $\mathrm{d}$-pulegone is used in combination with the secondary repellent anthraquinone (Orr-Walker et al. 2012). However, there is some evidence that this combination of anthraquinone and d-pulegone in cereal baits may reduce rat kills (Cowan et al. 2014; Crowell et al. 2015). Therefore, to use d-pulegone as a sensory cue and still achieve high rat kills with cereal baits, it may need to be paired with either a lower concentration of anthraquinone or a different secondary repellent. Reviews by Avery (2003) and Cowan et al. (this issue) outline alternatives including secondary repellents, with the latter focussing on repellent for pest control in the New Zealand context.

\section{Acknowledgements}

This work was completed as part of a DOC Innovation and Development project, and DOC Investigation number 4459. Many people have contributed to the choice of repellents to investigate and the development of project criteria and associated trial requirements. We would like to thank Tom Belton, Andy Cox, James Reardon, Clare Veltman, and Josh Kemp from the DOC project team for their good will and perseverance through all the design work and decision-making. We are grateful for the support of TBfree New Zealand (Simon Andrew, Paul Livingstone, Matthew Hickson), Landcare Research NZ Ltd (Sam Brown), the Kea Conservation Trust (Tamsin Orr-Walker, Nigel Adams, Corey Mosen), and Animal Control Products (Bill Simmons, Craig Lewis). We thank Amanda Todd, Dave Morgan and an anonymous reviewer for valuable comments on an earlier version of the manuscript.

\section{References}

Avery M 2003. Avian repellents. In: Plimmer J, Gammon D, Ragsdale N eds Encyclopedia of agrochemicals. Hoboken, New Jersey, USA, John Wiley. Pp. 122-128.

Avery M, Decker D, Humphery J, Laukert C 1996. Mint plant derivatives as blackbird feeding deterrents. Crop Protection 15(5): 461-464.

Avery M, Humphrey J, Decker D 1997. Feeding deterrence of anthraquinone, anthracene, and anthrone to rice-eating birds. Journal of Wildlife Management 61(4): 1359-1365.

Avery M, Tillman E, Laukert C 2001. Evaluation of chemical repellents for reducing crop damage by Dickcissels in Venezuela. International Journal of Pest Management 47(4): 311-314.

Baser K, Kirimer N, Tumen G 1998. Pulegone-rich essential oils of Turkey. Journal of Essential Oil Research 10: 1-8.

Belant J, Ickes S, Tyson L, Seamans T 1997. Comparison of d-pulegone and mangone as cowbird feeding repellents. International Journal of Pest Management 43(4): 303-305.

Blyth R 2011. Comparative bait preference in captive Kea (Nestor notabilis). Unpublished RMB Consultants Ltd report for Animal Health Board. 21 p. http://www.tbfree. org.nz/comparative-bait-preference-in-captive-kea-2 . aspx (accessed 30 July 2015)

Booth L, Fisher P 2010. Bird repellents for 1080 baits. Unpublished report for Animal Health Board Project No. R-10719.15 p. http://www.tbfree.org.nz/bird-repellentsfor-1080-baits.aspx (accessed 30 July 2015).

Clapperton B, Morgan D, Day T, Oates K, Beath A, Cox N, Matthews L 2014. Efficacy of bird repellents at deterring North Island robins (Petroica australis longipes) and tomtits (P. macrocephala toitoi) from baits. New Zealand Journal of Ecology 38(1): 116-123.

Clapperton B, Porter R, Day T, Waas J, Matthews L 2012. Designer repellents: combining olfactory, visual or taste cues with a secondary repellent to deter free-ranging 
house sparrows from feeding. Pest Management Science 68: 870-877.

Cowan P, Booth L, Crowell M 2015. Repellents with potential to protect kea and other native birds from aerial poisoning for possum and rat control. New Zealand Journal of Ecology 40: 29-41.

Cowan P, Brown S, Forrester G, Booth L, Crowell M 2014. Bird-repellent effects on bait efficacy for control of invasive mammal pests. Pest Management Science. doi: $10.1002 /$ ps. 3887

Crowell M, Broome K 2004. Risk assessment system for pesticides used by Department of Conservation. DOC Science Internal Series 184. Wellington, Department of Conservation. $9 \mathrm{p}$.

Crowell M, Martini M, Moltchanova E 2015. Effect of the addition of bird repellents to aerially applied 1080 baits on rat and possum abundance. New Zealand Journal of Ecology 40: 48-59.

Day T, Matthews L, Flight K, Aukett M 2000: Low-cost bird repellents for possum baits. Unpublished AgResearch Ltd report to Animal Health Board. 27 p. http://www.tbfree. org.nz/low-cost-bird-repellants-for-possum-baits.aspx (accessed 18 August 2015).

Day T, Matthews L, Waas J 2003. Repellents to deter New Zealand's North Island robin Petroica australis longipes from pest control baits. Biological Conservation 114: 309-316.

Day T, Clapperton B, Porter R, Waas J, Matthews L 2012. Responses of free-ranging house sparrows to feed containing primary and secondary repellents. New Zealand Journal of Crop and Horticultural Science 40(2): 127-138.

Esther A, Tilcher R, Jacob J 2012. Assessing the effects of three potential chemical repellents to prevent bird damage to corn seeds and seedlings. Pest Management Science 69: 425-430.

Joshi R 2013. Pulegone and menthone chemotypes of Mentha spicata Linn. from Western Ghats Region of North West Karnataka, India. National Academy Science Letters 36(3): 349-352.

Madene A, Jacquot M, Scher J, Desobry S 2005. Flavour encapsulation and controlled release - a review. International Journal of Food Science and Technology 41: $1-21$.

Editorial board member: Kerri-Anne Edge

Received 12 November 2014; accepted 12 August 2015
Mason J 1990. Evaluation of d-pulegone as an avian repellent. Journal of Wildlife Management 54(1): 130-135.

Mastrota F, Mench J 1995. Evaluation of taste repellents with Northern bobwhites for deterring ingestion of granular pesticides. Environmental Toxicology and Chemistry 14(4): 631-638.

McIlroy J 1984. The sensitivity of Australian animals to 1080 poison VII. Native and introduced birds. Australian Wildlife Research 11: 373-385.

Orr-Walker T, Adams N, Roberts L, Kemp J, Spurr E 2012. Effectiveness of the bird repellents anthraquinone and d-pulegone on an endemic New Zealand parrot, the kea. Applied Animal Behaviour Science 137 (1-2): 80-85.

Parkes J, Murphy E2003. Management of introduced mammals in New Zealand. New Zealand Journal of Zoology 30(4): 335-359.

R Core Team 2013. R: A language and environment for statistical computing. Vienna, Austria, R Foundation for Statistical Computing. ISBN 3-900051-07-0. http:// www.R-project.org/ (accessed 18 August 2015).

Spurr E 2008. Bird (kea) repellent research. unpublished Report TO the Kea Conservation Trust. 5 p. Available on request from the Kea Conservation Trust www.keaconservation. co.nz (accessed 18 August 2015).

van Klink P, Crowell M 2015. Kea (Nestor notabilis) survivorship through a 1080 operation using cereal baits containing the bird repellent d-pulegone at Otira, central Westland. DOC Research and Development Series 344. Wellington, Department of Conservation. $13 \mathrm{p}$.

Wager-Page S, Mason J 1996. Exposure to volatile d-pulegone alters feeding behaviour in European starlings. Journal of Wildlife Management 60(4): 917-922.

Werner S, Tupper S, Pettit S, Carlson J, Linz G 2011. Anthraquinone repellent to reduce take of non-target birds from zinc phosphide rodenticide applications. Applied Animal Behaviour Science 135: 146-153.

Weser C, Ross J 2012. The effect of colour on bait consumption by kea (Nestor notabilis): implications for deterring birds from toxic baits. New Zealand Journal of Zoology 40(2): 137-144. 